\title{
Erratum to: On Robots and Insurance
}

\author{
Andrea Bertolini $^{1}$ - Pericle Salvini $^{2}$. Teresa Pagliai ${ }^{3}$ - Annagiulia Morachioli ${ }^{2}$. \\ Giorgia Acerbi $^{2}$ - Leopoldo Trieste ${ }^{4}$ - Filippo Cavallo ${ }^{2}$. Giuseppe Turchetti ${ }^{4}$. \\ Paolo Dario ${ }^{2}$
}

Published online: 7 June 2016

(C) Springer Science+Business Media Dordrecht 2016

\section{Erratum to: Int J of Soc Robotics DOI 10.1007/S12369-016-0345-z}

In the following paper: "On Robots and Insurance" (DOI: 10.1007/s12369-016-0345-z), this next sentence was inadvertently omitted from the acknowledgement section: “..." and "Echord ++ The European Coordination Hub for Open Robotics Development, GA 601116".

Springer regrets this omission and would like to apologize for any inconvenience caused.

The online version of the original article can be found under doi:10.1007/S12369-016-0345-z.

Pericle Salvini

p.salvini@sssup.it

1 DIRPOLIS Institute, Scuola Superiore Sant'Anna, Piazza Martiri della Libertà, 33, 56127 Pisa, PI, Italy

2 BioRobotics Institute, Scuola Superiore Sant'Anna, Viale Rinaldo Piaggio, 34, 56025 Pontedera, PI, Italy

3 TechnoDeal, Viale Boccioni, 2, 56037 Peccioli, PI, Italy

4 Institute of Management, Scuola Superiore Sant'Anna, p.zza Martiri della libertà 24, 56127 Pisa, PI, Italy 